\title{
Keputusan Petani Kopi Arabika Dalam Mengambil Kredit Di Sumatera Utara
}

\author{
Sri Fajar Ayu ${ }^{1^{*}}$ \\ S. Hotmarida ${ }^{2}$ \\ 1,2 Magister Agribisnis, Fakultas Pertanian, Universitas Sumatera Utara \\ *email :srifajar.ayu@gmail.com \\ Diterima: Mei 2020, Disetujui: September 2020, Dipublish: Oktober 2020
}

\begin{abstract}
Abstrak
Kopi merupakan salah satu komoditas ekspor Indonesia yang cukup penting sebagai penghasil devisa negara selain minyak dan gas. Modal menjadi permasalahan penting bagi perkebunan kopi rakyat di Sumatera Utara. Penambahan modal diharapkan akan meningkatkan produksi kopi. Ketersediaan kredit menyebabkan memungkinkannya dilakukan proses produksi dan konsumsi yang lebih baik, meningkatkan kesejahteraan petani sehingga memberikan hasil produksi yang lebih baik. Faktor- faktor yang mempengaruhi pengambilan kredit adalah mendapatkan peningkatan akses layanan tabungan dan pinjaman untuk pertanian. Penelitian ini dilakukan di Provinsi Sumatera Utara dengan tujuan untuk menganalisis faktor-faktor keputusan petani kopi arabika dalam mengambil kredit di Provinsi Sumatera Utara dan menganalisis faktor-faktor yang mempengaruhi jumlah kredit yang diambil oleh petani kopi arabika di Provinsi Sumatera Utara Metode yang dilakukan dalam penelitian ini adalah Analisis Faktor dan Analisis Regresi Linear Berganda. Sampel dalam penelitian ini terdiri dari 150 responden petani kopi arabika yang terdiri dari 75 orang petani kopi yang mengambil kredit dan 75 orang petani kopi yang tidak mengambil kredit. Hasil penelitian menunjukkan bahwa faktorfaktor yang mempengaruhi keputusan petani kopi arabika dalam mengambil kredit adalah aspek pribadi petani, kesesuaian penawaran kredit, jaminan kredit dan sifat usahatani kopi dan Faktor-faktor yang mempengaruhi jumlah kredit yang diambil oleh petani kopi arabika di Provinsi Sumatera Utara adalah aspek pribadi petani, kesesuaian penawaran kredit , jaminan kredit dan sifat usahatani kopi, namun faktor aspek pribadi petani adalah faktor yang sangat besar pengaruhnya (signifikan) terhadap jumlah kredit yang diambil di Provinsi SumateraUtara.
\end{abstract}

Kata Kunci : Kopi, Kredit, Usahatani Kopi

\begin{abstract}
Coffee is one of Indonesia's export commodities which is quite important as a source of foreign exchange in addition to oil and gas. Capital is an important issue for smallholder coffee plantations in North Sumatra. The additional capital is expected to increase coffee production. The availability of credit makes it possible for better production and consumption processes to be carried out, increasing the welfare of farmers so as to provide better production results. the factors that influence credit taking is getting increased access to savings and loan services for agriculture. This research was conducted in North Sumatra Province with the aim of analyzing the decisions of Arabica coffee farmers in taking credit in North Sumatra Province and to analyze the factors that influence the amount of credit taken by Arabica coffee farmers in North Sumatra Province. The method used in this research is factor analysis and multiple linier regression analysis. The sample in this study consisted of 150 arabica coffee farmer respondents consisting of 75 coffee farmers who took credit and 75 coffee farmers who did not take credit. The results showed that the factors that influenced the decisions of Arabica coffee farmers in taking credit were the personal aspects of the
\end{abstract}


farmers, the suitability of credit offers, credit guarantees and the nature of coffeefarmingand The factors that affect the amount of credit taken by Arabica coffee farmers in North Sumatra Province are the personal aspects of the farmers, the suitability of credit offers, credit guarantees and the nature of coffee farming, but the personal aspects of the farmers are the factors that have a very big (significant) effect on the amount credit taken in North Sumatra Province.

Keyword : Coffee, Credit, Coffee Farming

\section{PENDAHULUAN}

Kopi merupakan salah satu komoditi hasil perkebunan yang memiliki peranan penting dalam kegiatan perekonomian di Indonesia. Kopi juga merupakan salah satu komoditas ekspor Indonesia yang cukup penting sebagai penghasil devisa negara selain minyak dan gas. Selain mempunyai peluang ekspor yang semakin terbuka, pasar kopi di dalam negeri masih cukup besar (BPS Indonesia, 2017).

Provinsi Sumatera utara merupakan salah satu daerah penghasil kopi arabika dan robusta terbaik di dunia sudah diakui kualitasnya menembus sampai pasar internasional. Adanya produksi kopi di Sumatera Utara ini memberikan kontribusi penting terhadap perekonomian masyarakat di daerah sentra produksi kopi di Sumatera Utara , baik berupaproduk olahan dan sektor jasa. Keadaan ini juga tentunya didukung letak geografis, suhu dan curah hujan yang sesuai untuk pertumbuhannya sehingga luas kebun kopi cenderung meningkat (BPS Sumut, 2017).

Produksi perkebunan kopi di Sumatera Utara bertambah dari $58.840,03$ ton pada tahun 2018 menjadi $63.390,00$ ton pada tahun 2019 seiring dengan pertambahan jumlah luasan lahan dari 70.895,25 menjadi 93.070,00 pada tahun 2019 . Pertambahan produksi ini tidak terlalu signifikan dibandingkan dengan perkembangan luas lahannya. Hal ini disebabkan karena kebanyakan perkebunan kopi di Sumatera Utara diusahakan oleh perkebunan rakyat dengan modal yang sedikit. Padahal dengan penambahan modal yang sedikit saja dapat memberikan hasil yang sangat baik pada perkebunan kopi di Sumatera Utara mengingat kopi yang dihasilkan di Sumatera Utara sangat diminati di negara- negara tujuan ekspor (Dinas Perkebunan Sumatera utara,2019).

Modal menjadi permasalahan penting bagi perkebunan rakyat di Sumatera Utara. Penambahan modal diharapkan akan meningkatkan produksi kopi. Modal yang diperoleh melalui kredit akan memenuhi kebutuhan akan dana untuk penyiapan lahan, penanaman, pemeliharaan dan pemanenan. Ketersediaan kredit menyebabkan memungkinkannya dilakukan proses produksi dan konsumsi yang lebih baik, meningkatkan kesejahteraan petani sehingga memberikan hasil produksi yang lebih baik (Astra, 2016)

Keputusan tidaklah secara tiba-tiba terjadi, melainkan melalui beberapa tahapan proses, keputusan dalam pengambilan kredit yang dilakukan oleh masyarakat untuk memecahkan masalah dalam bidang ekonomi merupakan salah satu tujuan yaitu untuk mengembangkan usaha atau modal usaha. Untuk bisa memutuskan 
10.31289/agrica.v13i1.3105.g2501

mengambil kredit masyarakat telah mempertimbangkan faktor-faktor yang digunakan untuk mengambil kredit serta menjadi salah satu nasabah perusahaan pemberi sumber dana. (Hansson, 2005). Faktor- Faktor yang mempengaruhi pengambilan kredit adalah mendapatkan peningkatan akses layanan tabungan dan pinjaman untuk pertanian yang sangat mempengaruhi keputusan rumah tangga petani berpartisipasi dalam program kredit rumah tangga pertanian (Zech,2013).

Sehingga berdasarkan pendahuluan maka perlu dikaji mengenai faktor-faktor keputusan petani kopi arabika dalam mengambil kredit di Provinsi Sumatera Utara dan faktor-faktor yang mempengaruhi jumlah kredit yang diambil oleh petani kopi arabika di Provinsi Sumatera Utara.

\section{METODOLOGI PENELITIAN}

Penelitian ini dilakukan secara sengaja pada Provinsi Sumatera Utara yang berarti bahwa kabupaten yang memiliki produktivitas tertinggi di Sumatera Utara dan mayoritas masyarakatnya mengusahakan budidaya kopi arabika yang dipilih menjadi lokasi penelitian yaitu Kabupaten Dairi, Kabupaten Karo, Kabupaten Tapanuli Utara, Kabupaten Tapanuli Selatan dan Simalungun. Berdasarkan pertimbangan bahwa daerah ini merupakan sentra penghasil kopi di Sumatera Utara, banyak perkebunan rakyat yang belum menggunakan kredit.

Populasi dalam penelitian ini adalah seluruh petani kopi yang menggunakan kredit maupun petani kopi yang tidak menggunakan kredit di Sumatera Utara.
Pengambilan sampel dalam penelitian ini dilakukan secara purposive sampling terhadap petani kopi menggunakan kredit dan tidak menggunakan kredit sebanyak 150 responden yang terdiri dari 75 orang petani kopi yang mengambil kredit dan 75 orang petani yang tidak mengambil kredit.

Pengumpulan data dalam penelitian ini dilakukan dengan metode pengumpulan data primer dan sekunder. Data primer diperoleh melalui wawancara dan diskusi secara langsung kepada responden, yaitu petani yang menggunakan kredit koperasi dan petani yang tidak menggunakan kredit koperasi di Sumatera Utara. Data sekunder diperoleh dari instansi terkait yaitu BPS dan jurnal.

Metode analisis data yang digunakan

dalam penelitian ini adalah analisis faktor (Firdaus, 2011). Adapun variabel faktor-faktor yang mempengaruhi pengambilan kredit adalah modal, luas lahan, umur tanaman kopi, jumlah tanggungan keluarga, usia petani, tingkat suku bunga, pelayanan, prosedur penyaluran kredit, jangka waktu pengembalian, jaminan kredit, pendapatan, pengeluaran keluarga, sumber informasi, jarak ke sumber kredit, dan jenis sumber kredit. Dalam melakukan analisis faktor ada beberapa langkah yang perlu diperhatikan yaitu (Santoso, 2010):

Menentukan variabel- variabel yang akan dianalisis

Uji variabel

a. Uji Validitas dan Reabilitas

Variabel digunakan dalam analisis harus diuji terlebih dahulu dengan uji validitas dan realibilitas. Jumlah responden dalam uji validitas ini 
10.31289/agrica.v13i1.3105.g2501

adalah 150 responden dengan 15 variabel pertanyaan. Pengujian validitas kuesioner penelitian ini menggunakan software SPSS 16 dengan metode Korelasi Pearson, Kaidah keputusan validitas yaitu (Priyatno, 2014):

a.jika rhitung $<$ rtabel maka tidak valid b.Jika rhitung $>$ rtabel maka valid Realibilitas kurang dari 0,6 adalah kurang baik, sedangkan 0,7 dapat diterima dan diatas 0,8 adalah baik(Priyatno, 2014).

a. Uji Keiser Meyier Olkin of Measure Sampling Adequancy (KMO-MSA). Pengujian ini bertujuan untuk menyaring variabel-variabel yang akan dianalisis agar memenuhi syarat untuk dianalisis lebih lanjut. Besarnya angka (KMOMSA)berkisar antara 0 hingga 1 dengan kriteria sebagai berikut (Norimawati, 2008):

Jika bernilai $=1$, maka variabel tersebut dapat diprekdisi dan dianalisis lebih lanjut.

Jika bernilai $<0,5$, maka variabel tersebut tidak dapat diprediksi dan dianalisis lebih lanjut

b. Factoring. Setelah mendapatkan variabel-variabel yang telah memenuhi syarat maka dilanjutkan dengan proses factoring (ekstraksi) menggunakan Principal Component Analysis(PCA)

c. Interpretasi, Interpretasi faktor dengan memberikan nama atas faktor yang membentuk sesuai dengan nilai loading factor atribut variabel yang tertinggi dalam satu komponen atau faktor.

Metode yang digunakan pada tujuan kedua yaitu menganalisis faktorfaktor yang mempengaruhi jumlah kredit yang diambil oleh petani kopi arabika di Provinsi Sumatera Utara menggunakan analisis regresi linear berganda.

Dalam analisis regresi hubungan antara variabel independent dan variabel dependent adalah dalam bentuk linier maka untuk itu fungsi persamaan yang digunakan dalam penelitian ini adalah:

$\mathrm{Y}=\mathrm{f}(\mathrm{X} 1, \mathrm{X} 2, \mathrm{X} 3, \mathrm{X} 4, \mathrm{X} 5)$

Dari fungsi tersebut diatas kemudian diderivasikan ke dalam model persamaan ekonometrika dalam bentuk Model Regresi Linier Berganda (Multiple Linier Regression) untuk melihat jumlah kredit yang diambil oleh petani kopi arabika di Sumatera Utara.

$Y=\alpha+\beta_{1} X_{1}+\beta_{2} X_{2}+\beta_{3} X_{3}+\beta_{4} X_{4}+\mu$

Dimana :

\begin{tabular}{|c|c|}
\hline Y & $\begin{aligned}= & \text { Jumlah Kredit yang } \\
\text { Diambil } & \end{aligned}$ \\
\hline$\alpha$ & Konstanta Intersep \\
\hline$\beta 1-\beta 4$ & $\begin{aligned}= & \text { Koefisien } \quad \text { Variabel } \\
& \text { Regresi }\end{aligned}$ \\
\hline $\mathrm{X}_{1}$ & Aspek PribadiPetani \\
\hline $\mathrm{X}_{2}$ & $\begin{aligned}= & \text { Kesesuaian } \\
& \text { Penawaran Kredit }\end{aligned}$ \\
\hline $\mathrm{X}_{3}$ & JaminanKredit \\
\hline $\mathrm{X}_{4}$ & $=$ Sifat UsahataniKopi \\
\hline$\mu$ & Random Error \\
\hline
\end{tabular}

Untuk menguji apakah variabel Aspek pribadi petani $\left(\mathrm{X}_{1}\right)$, Kesesuaian penawaran kredit ( $\left.\mathrm{X}_{2}\right)$, Jaminan Kredit $\left(X_{3}\right)$, Sifat Usahatani Kopi $\left(X_{4}\right)$, secara bersama - sama (simultan) berpengaruh terhadap jumlah kredit yang diambil (Y) maka digunakan uji $\mathrm{F}$ (Nazir, 2003).

\section{HASIL DAN PEMBAHASAN}

Uji validitas dilakukan terhadap pertanyaan untuk mengetahui sejauh manapertanyaan tersebut dapat mengukur objek yang diteliti. Uji 

10.31289/agrica/v12i2.3766

10.31289/agrica.v13i1.3105.g2501

validitas terhadap pertanyaan

dilakukan dengan mengkorelasi setiap nilai pertanyaan dengan nilai total pertanyaan
responden.Berikut hasil uji validitas untuk setiap pertanyaan berdasarkan pengolahan statistik dengan bantuan program SPSS.

Tabel 1. Hasil Uji Validitas

\begin{tabular}{|c|c|c|c|c|}
\hline No & Indikator & $\begin{array}{c}\mathbf{R} \\
\text { Hitung }\end{array}$ & $\begin{array}{c}\mathbf{R} \\
\text { Tabel }\end{array}$ & Keterangan \\
\hline 1 & Modal & 0,535 & & Valid \\
\hline 2 & Luas Lahan & 0,562 & & Valid \\
\hline & Umur Tanaman & & & \\
\hline 3 & $\begin{array}{l}\text { Kopi } \\
\text { Jumlah } \\
\text { Tanggungan }\end{array}$ & 0,678 & & Valid \\
\hline 4 & Keluarga & 0,619 & & Valid \\
\hline 5 & Usia Petani & 0,594 & & Valid \\
\hline 6 & $\begin{array}{l}\text { Pendapatan } \\
\text { Pengeluaran }\end{array}$ & 0,691 & & Valid \\
\hline 7 & Keluarga & 0,677 & & Valid \\
\hline 8 & $\begin{array}{l}\text { Suku Bunga } \\
\text { Jangka Waktu }\end{array}$ & 0,572 & 0,159 & Valid \\
\hline 9 & Pengembalian & 0,634 & & Valid \\
\hline 10 & $\begin{array}{l}\text { Jaminan } \text { Kredit } \\
\text { Jenis } \quad \text { Sumber }\end{array}$ & 0,456 & & Valid \\
\hline 11 & Kredit & 0,428 & & Valid \\
\hline 12 & $\begin{array}{l}\text { Pelayanan } \\
\text { Prosedur }\end{array}$ & 0,654 & & Valid \\
\hline 13 & $\begin{array}{l}\text { Penyaluran } \\
\text { Sumber }\end{array}$ & 0,539 & & Valid \\
\hline 14 & $\begin{array}{l}\text { Informasi } \\
\text { Jarak Sumber }\end{array}$ & 0,547 & & Valid \\
\hline 15 & Kredit & 0,624 & & Valid \\
\hline
\end{tabular}

Sumber : Data Primer diolah (2019)

Berdasarkan pada tabel 1 hasil uji validitas diketahui bahwa nilai koefisien korelasi ( $\mathrm{r}$ hitung) setiap pertanyaan dinyatakan valid, karena $r$ hitung yang dihasilkan lebih besar dari $r$ tabel 0,159. Hasil uji realibilitas dapat dilihat dari nilai cronbach Alpha. Nilai cronbach Alpha $>0,6$ maka ditanyakan sudah realibel atau konsisten. Berdasarkan pada tabel 1 hasil uji reabilitas dapat dilihat nilai cronbach alpha yaitu sebesar 0,866. nilai cronbach sebesar 0,866 menujukkan bahwa semua variabel dalam penelitian ini adalah realibel atau konsisten 
Tabel 2. Hasil Uji Reabilitas

\begin{tabular}{lllll}
\hline No & Indikator & r Tabel & Cronbach $\boldsymbol{\alpha}$ & $\begin{array}{c}\text { Reabilitas Cronbach }> \\
\text { r tabel }\end{array}$ \\
\hline 1 & Modal & & \\
2 & $\begin{array}{l}\text { Luas Lahan } \\
\text { Umur Tanaman }\end{array}$ & & \\
3 & Kopi & & \\
4 & Jumlah & & \\
& Tanggungan & 0,6 & 0,866 & \\
5 & Keluarga & & & \\
6 & Usia Petani & & \\
7 & Pendapatan & & \\
\hline
\end{tabular}

Sumber : Data Primer diolah (2019)

Pengujian KMO dan bartlett's Test digunakan untuk menunjukkan koefisisen antar variabel secara keseluruhan. Berdasarkan tabel dibawah dapat dilihat bahwa KMO (Kaiser Meyer Olkin) yang diperoleh adalah sebesar 0,727 > 0,50 dan nilai signifikansi 0,000 < 0,05. Sehingga dapat dikatakan bahwa model yang digunakan dalam penelitian ini sudah layak untuk dilakukan analisis faktor.

Tabel 3. Hasil Uji KMO and Bartlett's Test

\begin{tabular}{|c|c|c|}
\hline \multicolumn{3}{|l|}{ KMO and Bartlett's Test } \\
\hline Kaiser-Meyer-Olkin Measur & e of Sampling Adequacy. & ,727 \\
\hline \multirow[t]{3}{*}{ Bartlett's Test of Sphericity } & Approx. Chi-Square & $1,098 \mathrm{E} 3$ \\
\hline & Df & 105 \\
\hline & Sig. & 000 \\
\hline
\end{tabular}

Sumber : Data Primer diolah (2019)

Proses selanjutnya adalah factoring yaitu melakukan ekstraksi/reduksi variabel asli menjadi beberapa faktor yang dapat mewakili seluruh variabel asli dengan menggunakan metode principal Component Analisis (PCA). Tabel dibawah menunjukkan variabel yang digunakan apakah mampu untuk menjelaskan faktor atau tidak yang dibuktikan dengan nilai extraction $>0,50$. Seluruh variabel berdasarkan tabeldibawah memiliki nilai extraction > 0,50. Langkah selanjutnya adalah Penentuan jumlah factor yang terbentuk yang dapat dilihat pada nilai total eigenvalue >1.Penentuan jumlah faktor yang terbentuk yang dapat dilihat pada nilai total eigenvalue dibawah memiliki nilai extraction $>0,50$. Langkah selanjutnya Penentuan jumlah faktor yang terbentuk yang dapat dilihat pada nilai total eigenvalue yaitu $>1$ 


\begin{tabular}{lll}
\hline & Initial & Extraction \\
\hline Modal & 1,000 &, 644 \\
Luas Lahan & 1,000 &, 728 \\
Umur Tanaman Kopi & 1,000 &, 732 \\
Jumlah Tanggungan Keluarga & 1,000 &, 782 \\
Usia Petani & 1,000 &, 571 \\
Pendapatan & 1,000 &, 685 \\
Pengeluaran Keluarga & 1,000 &, 777 \\
Suku Bunga & 1,000 &, 787 \\
Jangka Waktu Pengembalian & 1,000 &, 553 \\
Jaminan Kredit & 1,000 &, 630 \\
Jenis Sumber Kredit & 1,000 &, 691 \\
Pelayanan & 1,000 &, 762 \\
Prosedur Penyaluran Kredit & 1,000 &, 596 \\
Sumber Informasi & 1,000 &, 648 \\
Jarak Sumber Kredit & 1,000 &, 613 \\
\hline
\end{tabular}

Sumber : Data Primer diolah (2019)

Berdasarkan tabel 4 pada bagian initial eigenvalues diperoleh bahwa jumlah faktor yang terbentuk adalah empat buah yaitu 5,271, 1,836, 1,861, dan 1,410 dan mampu menjelaskan sebesar 67,993 \% variasi. Langkah selanjutnya adalah mengelompokkan variabel sesuai dengan korelasinya terhadap masing- masing faktor dengan. Pada tabel factor yang lebih dari 0,5 masuk ke dalam faktor tersebut.Pemberian nama faktor pada tabel 6 berdasarkan nilai faktor variabel asli yang terbesar dari masing- masing faktor, didapatkan 4 faktor yang mempengaruhi petani kopi arabika di Sumatera Utara dalam mengambil kredit. Urutan faktor yang paling dominan mempengaruhi petani kopi arabika dalam mengambil kredit dapat dilihat melalui nilai keragaman yang dapat dijelaskan oleh masingmasing faktor.

Pemberian nama faktor (appendix 2) berdasarkan nilai faktor variabel asli yang terbesar dari masing- masing faktor, didapatkan 4 faktor yang mempengaruhi petani kopi arabika di Sumatera Utara dalam mengambil kredit. Urutan faktor yang paling dominan mempengaruhi petani kopi arabika dalam mengambil kredit dapat dilihat melalui nilai keragaman yang dapat dijelaskan oleh masingmasing faktor.

Pemberian nama faktor pada tabel berdasarkan nilai factor variabel asli yang terbesar dari masing- masing faktor, didapatkan 4 faktor yang mempengaruhi petani kopi arabika di Sumatera Utara dalam mengambil kredit. Urutan faktor yang paling dominan mempengaruhi petani kopi arabika dalam mengambil kredit 
10.31289/agrica.v13i1.3105.g2501

dapat dilihat melalui nilai keragaman yang dapat dijelaskan oleh masingmasing factor.

Pada appendix 1 menunjukkan urutan faktor- faktor yang mempengaruhi petani kopi dalam mengambil kredit. Tabel berikut menunjukkan urutan faktor- faktor yang mempengaruhi petani kopi dalam mengambil kredit

Tabel 5.Urutan yang Mempengaruhi Petani Kopi dalam Mengambil Kredit

\begin{tabular}{clc}
\hline No & Faktor & Variance (\%) \\
\hline 1 & Faktor Aspek Pribadi Petani & $35 ., 142$ \\
2 & Faktor Kesesuaian Penawaran Kredit & 12,242 \\
3 & Faktor Jaminan Kredit & 11,207 \\
4 & Faktor Sifat Usahatani Kopi & 9,403 \\
\hline
\end{tabular}

Sumber : Data Primer diolah (2019)

Berikut ini adalah Analisis Regresi Linier Berganda untuk menganalisis faktor-faktor yang mempengaruhi jumlah kredit yang diambil oleh petani kopi arabika di Provinsi Sumatera Utara merupakan analisis yang memiliki variabel bebas lebih dari satu disebut analisis regresi linier berganda. Teknik regresi linier berganda digunakan untuk mengetahui ada tidaknya pengaruh signifikan dua atau lebih variabel bebas

Tabel 8. Analisis Uji Hipotesis secara bersama-sama atau uji F

\begin{tabular}{|c|c|c|c|c|c|c|}
\hline Model & Sum of Squares & $\mathrm{df}$ & & Mean Square & $\mathrm{F}$ & Sig. \\
\hline Regression & $9,487 \mathrm{E} 14$ & 4 & & 2,372E14 & 3,307 &, $015^{\mathrm{a}}$ \\
\hline Residual & 5,021E15 & & 70 & 7,172E13 & & \\
\hline Total & $5,969 \mathrm{E} 15$ & & 74 & & & \\
\hline
\end{tabular}

Sumber : Data Primer diolah (2019)

Dari tabel diatas diperoleh Fhitung $=$ 3,307 dan $\mathrm{F}_{\text {tabel }}=1,86$, karena $\mathrm{F}_{\text {hitung }}=$ 3,307 $>F_{\text {tabel }}=1,86$, maka disimpulkan terima $\mathrm{H}_{\mathrm{a}}$ dan tolak $\mathrm{H}_{0}$ dalam hal ini dapat diartikan secara bersama-sama variabel aspek pribadi petani, kesesuaian penawaran kredit, jaminan kredit dan sifat usahatani berpengaruh terhadap jumlah kredit yang diambil oleh petani kopi arabika di Provinsi Sumatera Utara.

\section{Uji Hipotesis Parsial (Uji t)}

Uji t digunakan untuk menguji secara pasial masing-masing variabel. Variabel Independen terhadap Variabel Dependen. Jika probabilitas nilai $\mathrm{t}$ atau signifikan $<0,05$ maka dapat dikatakan bahwa terdapat pengaruh antara variabel bebas terhadap variabel terikat secara parsial. Pada Tabel 10 dapat kita lihat pengaruh variabel independent terhadap variabel terikat. 
Tabel 9. Analisis Uji Hipotesis Secara Parsial atau uji T

\begin{tabular}{|c|c|c|c|c|c|}
\hline \multirow[t]{2}{*}{ Model } & \multicolumn{2}{|c|}{$\begin{array}{l}\text { Unstandardized } \\
\text { Coefficients }\end{array}$} & \multirow{2}{*}{\multicolumn{2}{|c|}{$\begin{array}{c}\begin{array}{c}\text { Standardized } \\
\text { Coefficients }\end{array} \\
\text { Beta }\end{array}$}} & \multirow[b]{2}{*}{ Sig. } \\
\hline & B & Std. Error & & & \\
\hline 1 (Constant) & 37691,7 & $1,113 \mathrm{E} 7$ & & & 997, 003, \\
\hline Aspek Pribadi Petani & 701160,9 & 236270,7 & & 340 & 2,968,004 \\
\hline $\begin{array}{l}\text { Kesesuaian Penawaran } \\
\text { Kredit }\end{array}$ & $-2,276 \mathrm{E} 6$ & 1,691E6 & &,- 177 & $1,346^{-}, 183$ \\
\hline Jaminan Kredit & $-2,653 \mathrm{E} 6$ & 1,791E6 & &,- 190 & $1,482^{-}, 143$ \\
\hline Sifat Usahatani Kopi & $-308198,114$ & $1,126 \mathrm{E} 6$ & &,- 033 & $-274,785$ \\
\hline
\end{tabular}

Sumber : Data Primer diolah (2019)

Berdasarkan tabel diatas maka diperoleh persamaan yang dibentuk untuk model regresi dapat dituliskan menjadi :

$$
\begin{aligned}
Y= & 37691,77+701160,961 X_{1}-2,276 X_{2} \\
& -2,653 X_{3}-308198,114 X_{4}
\end{aligned}
$$

\section{Faktor Aspek Pribadi Petani}

Variabel faktor aspek pribadi petani yang memiliki nilai loading tertinggi sebesar 0,695 yang merupakan faktor pertama yang paling dominan adalah faktor aspek pribadi petani, dengan nilai keragaman yang tinggi sebesar $35,142 \%$. Responden yang memberikan nilai tinggi pada faktor ini adalah responden yang menjadikan bahwa aspek pribadi petani paling penting pada pengambilan keputusan dalam pengambilan kredit untuk petani kopi arabika di Provinsi sumatera Utara.

Berdasarkan hasil analisis uji parsial, pengaruh Aspek pribadi petani terhadapjumlah kredit yang diambil diperoleh thitung $=2,968$ dan nilai tabel $=2,0$ yang artinya thitung $>$ tabel maka terima Ha dan tolak H0. Dengan nilai signifikansi 0,004<0,05, Hal ini dapat disimpulkan bahwa Aspek pribadi petani berpengaruh nyata (signifikan) terhadap jumlah kredit yang diambil. Menurut Zech (2013) pendapatan rumah tangga signifikan terhadap partisipasi rumah tangga petani dalam pengambilan program kredit. Menurut Kasmir (2012) prosedur kredit yang diterapkan akan sangat berpengaruh terhadap keputusan nasabah dalam mengambilkredit.

\section{Faktor Kesesuaian Penawaran Kredit}

Variabel faktor kesesuaian penawaran kredit memiliki nilai loading sebesar 0,69 yang merupakan salah satu faktor pengambilan keputusan dalam pengambilan kredit untuk petani kopi arabika di Provinsi Sumatera Utara. Faktor kesesuaian penawaran kredit merupakan salah satu faktor yang terbentuk dengan nilai keragaman sebesar12,242\%, faktor kesesuaian penawaran kredit yang diperhatikan petani kopi dalam mengambil keputusan kredit adalah mengambil kredit karena sesuai dengan jenis sumber kredit yang diinginkan. Berdasarkan hasil analisis uji parsial, 
10.31289/agrica.v13i1.3105.g2501

pengaruh kesesuaian penawaran kredit terhadap jumlah kredit yang diambil diperoleh thitung $=-1,346$ dan nilai tabel $=2,0$ yang artinya thitung $<$ ttabel maka tolak Ha dan terima H0. Dengan nilai signifikansi sebesar 0,183 > 0,05, Hal ini dapat disimpulkan bahwa Kesesuaian penawaran kredittidak berpengaruh nyata (signifikan) terhadap jumlah kredit yang diambil.

Hal ini sesuai dengan penelitian Fransisca dan Siregar dalam Maharani (2011) yang menyatakan bahwa jika jumlah kredit yang diambil bermasalah dapat menimbulkan keengganan perbankan untuk mengambil kredit yang ditawarkan.

\section{Faktor Jaminan Kredit}

Faktor ketiga adalah faktor jaminan kredit dengan indikator mengambil kredit karena kesesuaian penawaran kredit sesuai dengan yang diinginkan oleh petani kopi dalam mengambil kredit dengan nilai keragaman sebesar 11,207\% .Berdasarkan hasil analisis uji parsial, pengaruh jaminan kredit terhadap jumlah kredit yang diambil diperoleh thitung $=-1,482$ dan nilai tabel $=2,0$ yang artinya thitung $<$ tabel maka tolak Ha dan terima H0, dengan nilai signifikansi $0,142>0,05$. Jaminan kredit tidak berpengaruh nyata (tidak signifikan) terhadap jumlah kredit yang diambil. Menurut Brigsten et al (2003) bahwa kurangnya jaminan kredit akan mempengaruhi terhadap pengambilan kredit.

\section{Faktor Sifat Usahatani Kopi}

Faktor keempat adalah faktor sifat usahatani kopi dengan indikator modal sangat penting bagi usahatani kopi, berdasarkan pentingnya modal usahatani sehingga petani kopi mengambil kredit dengan nilai keragaman sebesar 9,403\%. Berdasarkan Hasil analisis uji parsial, pengaruh Sifat usahatani kopi terhadap jumlah kredit yang diambil diperoleh $t_{\text {hitung }}=-2,74$ dan nilai tabel $_{\text {ta }}=$ 2,0 yang artinya thitung $<$ tabel maka tolak $\mathrm{Ha}$ dan terima H0, Sifat usahatani tidak berpengaruh nyata (signifikan) terhadap jumlah kredit yang diambil. Unsur sifat usahatani kopi adalah modal sangat penting bagi usahatani kopi, berdasarkan pentingnya modal usahatani sehingga petani mengambil kredit. Hal ini sesuai dengan Astra (2016) yang menyatakan bahwa pengambilan kredit tidak hanya dipengaruhi oleh modal, namun banyak faktor lain yang lebihmempengaruhi.

\section{SIMPULAN}

Berdasarkan hasil penelitian dan analisis yang telah dilakukan, maka dapat disimpulkan bahwa faktorfaktor yang mempengaruhi keputusan petani dalam mengambil kredit adalah aspek pribadi petani, kesesuaian penawaran kredit, jaminan kredit dan sifat usahatani kopi. Faktor-faktor yang mempengaruhi jumlah kredit yang diambil oleh petani kopi arabika di Provinsi Sumatera Utara adalah aspek pribadi petani, kesesuaian penawaran kredit, jaminan kredit dan sifat usahatani kopi, namun faktor 
10.31289/agrica.v13i1.3105.g2501

aspek pribadi petani adalah faktor yang sangat besar pengaruhnya (signifikan) terhadap jumlah kredit yang diambil di Provinsi SumateraUtara.Kepada kreditur lebih memperhatikan lagi faktor-faktor apa saja yang mempengaruhi keputusan petani kopi arabika dalam mengambil kredit di Sumatera Utara guna untuk meningkatkan minat petani kopi arabika dalam mengambil kredit. Agar lebih meningkatkan lagi akses layanan kredit petani guna untuk meningkatkan minat petani dalam mengambil kredit untuk biaya produksi usahatani kopi arabika oleh petani kopi arabika di Provinsi Sumatera Utara.

\section{DAFTAR PUSTAKA}

Astra, S. 2016. Analisis Keputusan Pengambilan Kredit Dan Ekonomi RumahTangga Petani Kopi Di Kabupaten Pati. Tesis . Bogor : Institut Pertanian Bogor.

Badan Pusat Statistik Indonesia. 2017. Statistik Kopi Indonesia. Publikasi BPS. Jakarta.

Badan Pusat Statistik Sumatera Utara. 2017. Sumatera Utara Dalam Angka 2017.Publikasi BPS. Medan

Bigsten A, Collier P, Dercon S, Fafchamps $M$, Gauthier $B$, Gunning JW, Oduro A, Oostendrop R, Patillo C, Soderbom M, Teal F, Zewfack Credit constraints in manufacturing enterprises in Africa. J. Afr. Econ. 12(1):104125.
Chauke PK. 2013. Factors influencing access to credit: $A$ case study of smallholder farmers in the Capricorn district of South Africa. Afr. J. Agric. Res. 8(7):582-585.

Dinas Perkebunan Provinsi Sumatera Utara. Data produksi Kopi 2019-2020. Medan

Firdaus M, Herminti, Farid MA. 2011. Aplikasi Metode Kuantitatif Untuk Managemendan Bisnis. Bogor (ID): IPB Press.

Hansson, Sven Ove, 2005, Departmen of Philosophy and the History of Technology.Royal Institute of Technology (KTH), "Decision Theory"

Kasmir, 2012. Analisis Laporan Keuangan, PT. Raja Grafindo Persada, Jakarta.

Norimawati, U. 2008. Teknik- Teknik Analisis Multivariat Untuk Riset Ekonomi.Yogyakarta (ID) : Graha Ilmu

Priyatno, D. 2014. Pengolahan Data Terpraktis. Penerbit Andi. Yogyakarta (ID).

Raharjo, P.2012. Kopi Panduan Budidaya Dan Pengolahan Kopi Arabika Dan Robusta.Jakarta : Penebar Swadaya

Santoso, S. 2010. Statistik Multivariant. Jakarta (ID). Elex Media Komputindo.

Suratiyah, Ken. 2008. Ilmu Usahatani. Penebar Swadaya. Jakarta.

Zech, L.2013. Evaluating Credit Risk Exposure In Agriculture.Minneapolis : University Of Minnesota. 
Agrica (Jurnal Agribisnis Sumatera Utara) Vol.13 No.2/Oktober 2020 Available online http://ojs.uma.ac.id/index.php/agrica 10.31289/agrica/v12i2.3766

10.31289/agrica.v13i1.3105.g2501

Appendix 1.

Tabel Component Matrix

\begin{tabular}{|c|c|c|c|c|}
\hline & \multicolumn{4}{|c|}{ Component } \\
\hline & 1 & 2 & 3 & 4 \\
\hline Modal &, 502 & 034 &,- 244 &, 576 \\
\hline Luas Lahan &, 543 &,- 175 &,- 485 & ,409 \\
\hline Umur Tanaman Kopi & 672 & ,187 &,- 252 & ,427 \\
\hline Jumlah Tanggungan Keluarga & 619 & 081 &,- 426 &,- 460 \\
\hline Usia Petani & ,589 &,- 250 &,- 300 &,- 268 \\
\hline Pendapatan & ,695 & 113 &,- 360 &,- 246 \\
\hline Pengeluaran Keluarga & 687 & ,274 &,- 215 &,- 429 \\
\hline Suku Bunga &, 573 & ,528 & ,309 & ,290 \\
\hline Jangka Waktu Pengembalian & 657 & ,136 & 318 &,- 042 \\
\hline Jaminan Kredit & ,467 & ,330 & ,485 &,- 261 \\
\hline Jenis Sumber Kredit & ,433 & 659 & ,245 & ,096 \\
\hline Pelayanan & ,658 &,- 482 & ,260 & ,171 \\
\hline Prosedur Penyaluran Kredit &, 554 &,- 424 & ,317 &,- 094 \\
\hline Sumber Informasi &, 543 &,- 396 & ,442 & 012 \\
\hline Jarak Sumber Kredit & 624 &,- 452 & 140 &,- 025 \\
\hline
\end{tabular}

Sumber : Data Primer diolah (2019) 
10.31289/agrica.v13i1.3105.g2501

Appendix 2.

Tabel Faktor- Faktor yang Mempengaruhi Keputusan Petani Kopi dalam Pengambilan Kredit

\begin{tabular}{lll}
\hline Faktor & $\begin{array}{l}\text { Loading } \\
\text { Faktor }\end{array}$ & $\begin{array}{l}\text { Variance } \\
(\%)\end{array}$ \\
\hline Aspek Pribadi Petani & 0,695 & \\
Pendapatan & 0,687 & \\
Pengeluaran keluarga & 0,672 & \\
Umur tanaman kopi & 0,658 & \\
Pelayanan & 0,657 & \\
Jangka waktu pengembalian & 0,624 & 35,42 \\
Jarak sumber kredit & 0,619 & \\
Jumlah tanggungan keluarga & 0,589 & \\
Usia petani & 0,573 & \\
Tingkat suku bunga & 0,554 & \\
Prosedur penyaluran kredit & 0,543 & 12,242 \\
Sumber Informasi & 0,543 & \\
Luas lahan & & 11,207 \\
Kesesuaian Penawaran Kredit & 0,659 & \\
Jenis sumber kredit & & 9,403 \\
Jaminan Kredit & 0,485 & \\
Jaminan kredit & & \\
Sifat Usahatani Kopi & 0,576 & \\
Modal & & \\
\hline
\end{tabular}

Sumber : Data Primer diolah (2019) 